\title{
New record and description of the male of Choreborogas puteolus Achterberg, 1995 (Hymenoptera, Braconidae, Rogadinae)
}

\author{
Penteado-Dias, AM. ${ }^{\mathrm{a} *}$ and Ramiro, Z.A. ${ }^{\mathrm{b} *}$ \\ ${ }^{a}$ Departamento de Ecologia e Biologia Evolutiva, Universidade Federal de São Carlos - UFSCar, \\ CP 676, CEP 13565-905, São Carlos, SP, Brazil

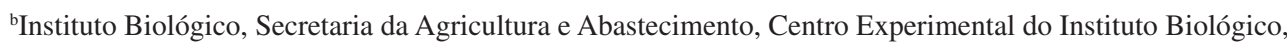 \\ Rod. Heitor Penteado, km 3, Vila Brandina, CEP 13001-970, Campinas, SP, Brazil \\ *e-mail: angelica@ufscar.br, zramiro@uol.com.br \\ Received November 19, 2008 - Accepted November 26, 2008 - Distributed August 31, 2009
}

(With 7 figures)

Choreborogas species are endoparasitoids of leafmining larvae of the Lepidoptera Lyonetiidae and Gracillariidae; the mummified host larva or prepupa is used as shelter during pupation. Emergence is from near the head end of the host (Whitfield, 1990).

After Achterberg (1995) the genus can be characterised by malar suture distinct (Figures 1,2); costulae of propodeum absent or short (Figures 3, 4); vein r-m of forewing absent and no quadrangular, second submarginal cell present; vein $r$ of forewing issued near basal third of pterostigma; vein CU1b of forewing absent; no ven-
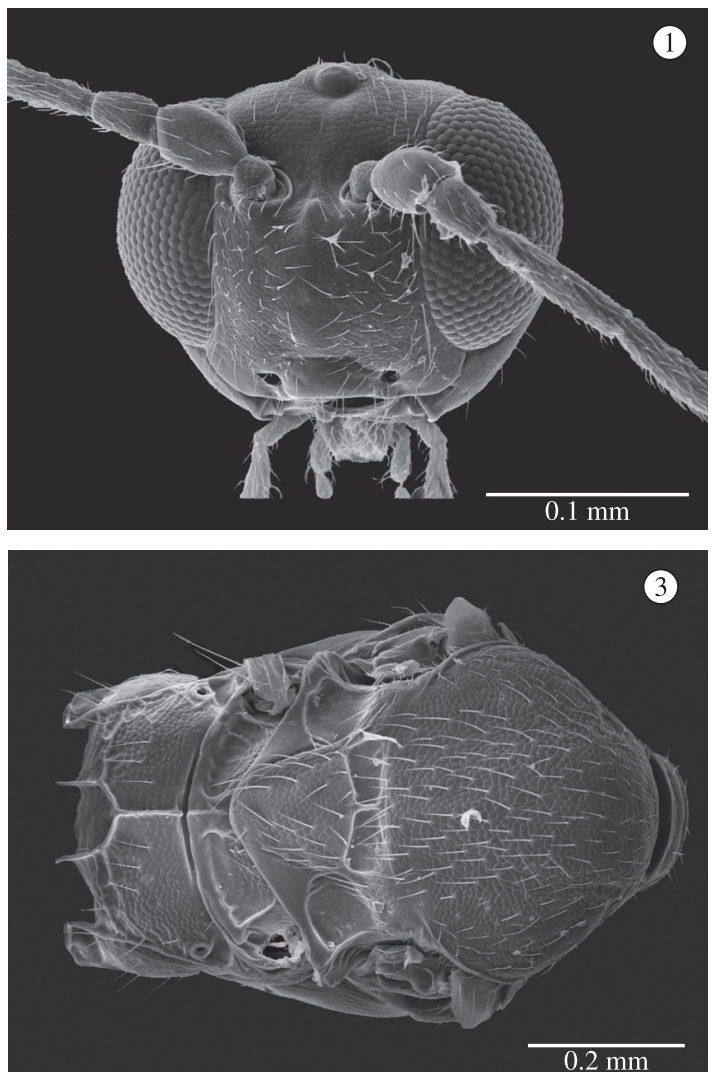

Figures 1-4. Choreborogas puteolus. Figures 1, 3, 5, female; 2, 4, 6, 7 male. 1, 2, head (front aspect); 3, 4, mesosoma (dorsal aspect); 5, 6, metasoma (dorsal aspect); 7, habitus.
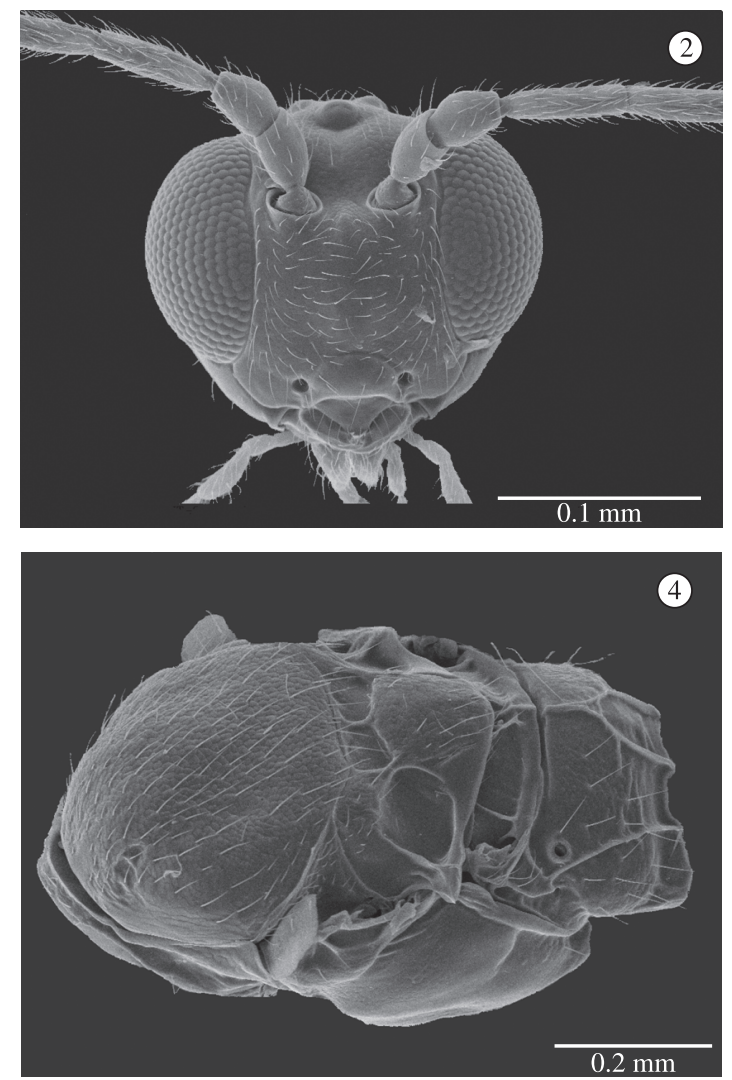

tral tooth on hind femur; hind femur more or less swollen; fore telotarsus comparatively wide; second and third tergites distinctly widened posteriorly (Figures 5, 6); hypopygium of female medium-sized and apically truncate.This is a medium-sized genus with eight species described distributed in the New World, mainly in the Neotropical region (Yu et al., 2005).

Achterberg (1995) described the female of C. puteolus with the holotype collected at light, in Panama. This species is characterised by vertex flat, not upper level of eyes, distinctly granulate (Figures 1,2); 

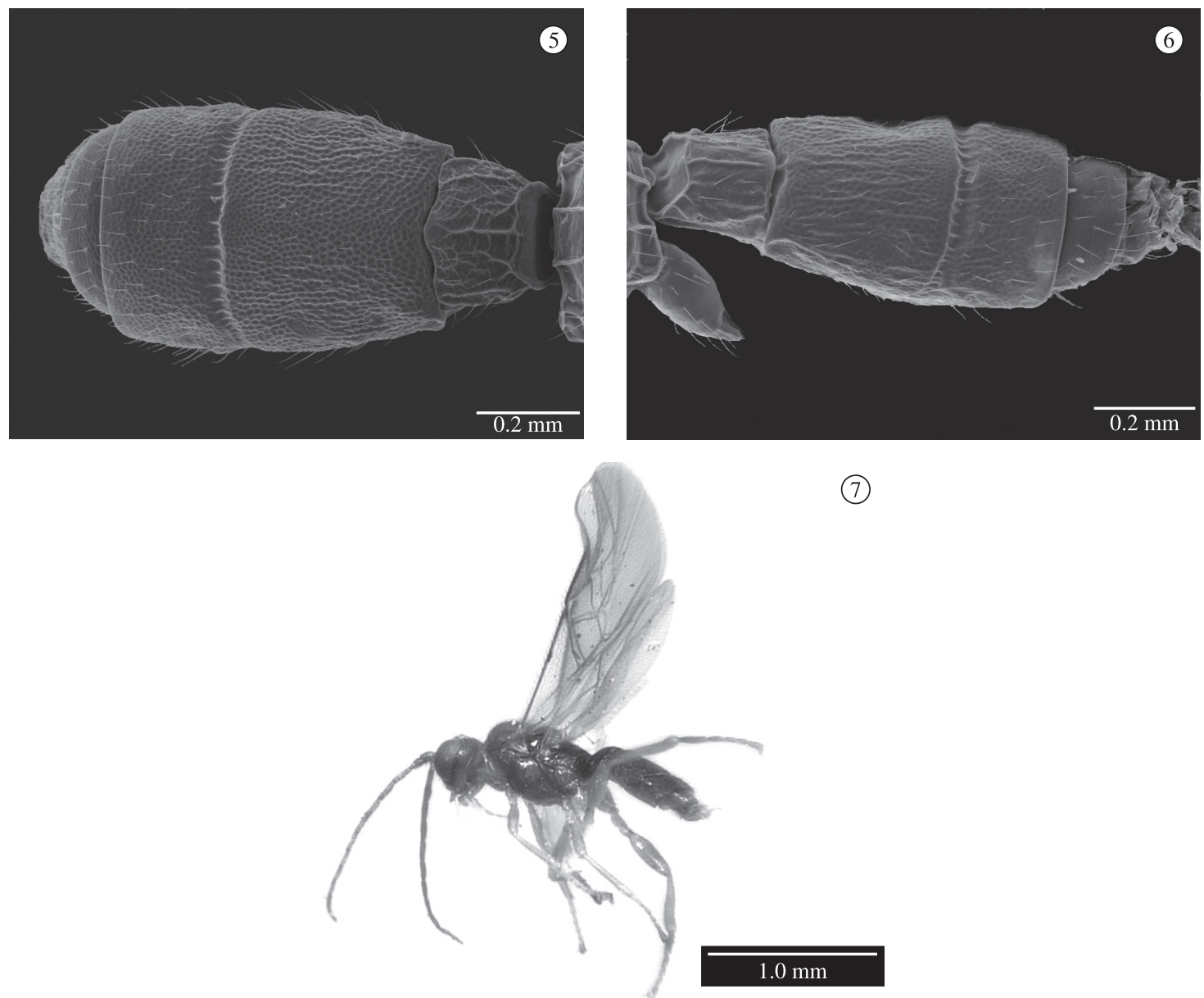

Figures 5-7. Choreborogas puteolus. Figures 1, 3, 5, female; 2, 4, 6, 7 male. 1, 2, head (front aspect); 3, 4, mesosoma (dorsal aspect); 5, 6, metasoma (dorsal aspect); 7, habitus.

antenna brownish; vein $\mathrm{r}$ of fore wing comparatively long, slightly shorter than width of pterostigma and emerging near basal 0.5 of pterostigma; vein 2-R1 absent; r:3SR+SR1:2-SR = 1:50:16; 1-CU1:2-Cu = 3:13. Hind wing: $\mathrm{M}+\mathrm{CU}: 1-\mathrm{M}=15: 23$. The hind femur of the female is at most some swollen, median carina of propodeum 0.4 times length of propodeum in lateral view (Figures 3, 4); median carina of second tergite obsolescent; vertex convex; second tergite with shallow pit antero-laterally (Figures 5,6) or with curved carina.

At this time we describe the male of this species (Figures 2, 4, 6, 7), comparing with the female (Figures 1, 3, 5), using material collected at the coffee plantation in the municipality of Monte Mor, in the State of São Paulo, Brazil, with white (20.I.2006 at the level of the ground; 21.XII.2005, at $1.5 \mathrm{~m}$ high), blue (28.IX.2005, at $1.0 \mathrm{~m} \mathrm{high)} \mathrm{and} \mathrm{yellow} \mathrm{(7.XII.2005,}$ at $0.5 \mathrm{~m}$ high) coloured pan traps. The specimens are at the DCBU collection (Collection of the Department of Ecology and Evolutionary Biology at the Federal University of São Carlos, São Carlos, SP, Brazil).
The male is similar to the female, but its antenna presents 13 antennomeres like the male of C. brevicarinatus and C. bulbofemoralis (Achterberg, 1995); the female presents 14 antennomeres.

Acknowledgements - To CNPq (Conselho Nacional de Desenvolvimento Científico e Tecnológico) and FAPESP (Fundação de Amparo à Pesquisa do Estado de São Paulo) for financial support.

\section{References}

ACHTERBERG, C. Van 1995. Generic revision of the subfamily Betylobraconinae (Hymenoptera: Braconidae) and other groups with modified fore tarsus. Zoologische Verhandelingen, no. 298, $242 \mathrm{p}$.

WHITFIELD, JB. 1990. Phylogenetic review of the Stiropius group of genera (Hymenoptera: Braconidae, Rogadinae) with description of a new neotropical genus. Proceedings of the Entomological Society of Washington, vol. 92, no. 1, p. 36-43.

YU, D. ACHTERBERG, C.Van and HORSTMANN, K. 2005. Catalogue of Ichneumonoidea (Hymenoptera). [S.1.]: [s.n.]. TAXAPAD (CD). 